Luciana de Melo Nunes Lopes ${ }^{1}$

Tiago Lopes Coelho ${ }^{1}$ Semíramis Domingues Diniz ${ }^{1}$ Eli Iola Gurgel de Andrade ${ }^{1}$

\title{
JUDICIALIZAÇÃO E JURISPRUDÊNCIA: UTILIZAÇÃO DA STA 175/CE EM ACÓRDÃOS EM SAÚDE NO ESTADO DE MINAS GERAIS
}

Judicialization and jurisprudence: Suspension of advance relief on collegiate decisions in healthcare in the state of Minas Gerais, Brazil

${ }^{1}$ Universidade Federal de Minas Gerais. Belo Horizonte/MG, Brasil.

Correspondência: Luciana de Melo Nunes Lopes. E-mail: lucianamnlopes@gmail.com

Recebido: 19/01/2018. Revisão: 27/08/2018. Aprovado: 18/09/2018. 


\section{RESUMO}

Após audiência pública em 2009, o Supremo Tribunal Federal consolidou conclusões no julgamento da Suspensão de Tutela Antecipada 175/CE, estabelecendo parâmetros que orientariam o Judiciário e racionalizariam o fenômeno da judicialização da saúde no Brasil. Desconhece-se, contudo, em que medida tal jurisprudência tem influenciado as decisões judiciais. O presente trabalho tem como objetivo investigar o uso da suspensão como referência a embasar as decisões finais colegiadas em saúde do Tribunal de Justiça do Estado de Minas Gerais. Trata-se de estudo de caso baseado em dados secundários obtidos nos acórdãos com citação da Suspensão de Tutela Antecipada 175/CE na ementa. Foram identificados 106 acórdãos. A suspensão foi citada em todos os anos desde 2009, principalmente em 2015, 2016 e 2017. A distribuição das citações entre relatores e órgãos julgadores foi heterogênea, e o principal contexto de uso da jurisprudência $(90,6 \%)$ foi para declarar a necessidade de priorização dos tratamentos ofertados pelo Sistema Único de Saúde e comprovação da excepcionalidade dos casos inadequados a eles. Estimou-se que os 106 acórdãos representaram $0,1 \%$ do universo de acórdãos sobre o direito à saúde proferidos no período. Concluiu-se que a Suspensão de Tutela Antecipada 175/CE não foi referência fortemente utilizada nos acórdãos do Tribunal de Justiça do Estado de Minas Gerais. Embora a literatura indique uma tendência à racionalidade na jurisprudência brasileira em relação ao deferimento de demandas judiciais em saúde, o frágil uso da jurisprudência do Supremo Tribunal Federal pela corte mineira não confirma, na prática, tal tendência, pondo em questão a efetividade de tal recurso na intervenção sobre o fenômeno da judicialização da saúde.

\section{Palavras-Chave}

Direito à Saúde; Judicialização da Saúde; Sistema Único de Saúde.

\section{ABSTRACT}

After a public hearing in 2009, the Brazilian Federal Supreme Court consolidated conclusions in the decision about the Suspension of Advance Relief 175/CE, establishing parameters that would guide the Judiciary and rationalize the judicialization of health in Brazil. Nevertheless, it's still not known to what extent the jurisprudence has influenced juridical decisions. This work aims to investigate the usage of the suspension as a reference to give base to the final collegiate decisions on health of the Court of Justice of the State of Minas Gerais. This is a case study based on secondary data found within collegiate judgments that cited the Suspension of Advance Relief 175/CE in their abstracts. 106 judgments were identified. The suspension was cited every year since 2009, especially in 2015, 2016 and 2017. The distribution of quotations among rapporteurs and courts was heterogeneous and the main context where the jurisprudence was used $(90,6 \%)$ was to establish the need to prioritize treatments offered by the Brazilian National Health System and to prove cases that are an exception to this. It was estimated that the 106 judgments represented $0,1 \%$ of the universe of collective judgments about the right to health during the studied period. The conclusion was that the suspension was not a reference strongly used in collective judgments by the Court of Justice of the State of Minas Gerais. Although the literature indicates a rational trend within the Brazilian jurisprudence when it comes to favorable decisions to judicial demands involving health issues, the scarce use of the suspension by the Court of Justice of the State of Minas Gerais does not confirm this tendency and rises questions on its effectiveness in the interventions in cases of judicialization of health.

\section{Keywords}

Right to Health; Judicialization of Health; Brazilian National Health System. 


\section{Introdução}

Tem sido denominado judicialização da saúde o fenômeno de invocação do Poder Judiciário para resolução de conflitos em saúde, especialmente aqueles envolvendo a garantia de assistência médica e farmacêutica. No Brasil, seu início remonta a meados da década de 1990, quando ativistas da sociedade civil requisitaram, via Justiça, o acesso a medicamentos para tratamento da Aids, embasados no artigo 196 da Constituição Federal de 1988 (CF/88), que dispõe ser a saúde direito de todos e dever do Estado ${ }^{1,2,3}$. Desde então, observa-se grande crescimento de demandas judiciais no setor de saúde e, consequentemente, aumento no gasto para atendê-las. Em 2015, a União gastou R\$ 1 bilhão com a judicialização da saúde um aumento de $1.300 \%$ em sete anos ${ }^{4}$. No mesmo ano, 15.383 processos deferidos foram recebidos pela Secretaria de Estado de Saúde de Minas Gerais (SES/MG). Já em 2017, foram recebidos 15.676 processos pela SES/MG ${ }^{5}$. Naquele ano, esperava-se um gasto conjunto de R 7 bilhões pela União, estados e municípios para atendimento às demandas judiciais em saúde 6 .

As discussões sobre o tema são polêmicas e complexas ${ }^{7,8}$, sobretudo porque exigem que os operadores do Direito se arrisquem em terrenos distantes de seu cotidiano de reflexão.

A fim de aprimorar o debate em um contexto no qual a crescente judicialização apontava para uma irracionalidade da atuação judicial, o então presidente do Supremo Tribunal Federal (STF), ministro Gilmar Mendes, convocou em 2009 uma audiência pública que ouviu especialistas de diversas áreas do conhecimento

\footnotetext{
${ }^{1}$ GOUVÊA, Marcos Maselli. O direito ao fornecimento estatal de medicamentos. Revista Forense, Rio de Janeiro, v. 99, n. 370, p. 103-134, nov./dez. 2003. [BuscaLegis.ccj.ufsc.br]. Disponível em: http://www. egov.ufsc.br/portal/sites/default/files/anexos/15709-15710-1-PB.pdf.

${ }^{2}$ VENTURA, Miriam et al. Judicialização da saúde, acesso à justiça e a efetividade do direito à saúde. Physis [online], Rio de Janeiro, v. 20, n. 1, p. 77-100, jan./fev. 2010. http://dx.doi.org/10.1590/ S0103-73312010000100006. Disponivel em: http://www.scielo.br/scielo.php?pid=S0103$73312010000100006 \&$ script=sci_abstract $\&$ tlng=es.

${ }^{3}$ MACHADO, Felipe Rangel de Souza. Contribuições ao debate da judicialização da saúde no Brasil. Revista de Direito Sanitário, São Paulo, v. 9, n. 2, p. 73-91, jul./out. 2008. http://dx.doi.org/10.11606/issn.23169044.v9i2p73-91. Disponível em: http://www.revistas.usp.br/rdisan/article/view/13118.

${ }^{4}$ AUMENTAM os gastos públicos com judicialização da saúde. Tribunal de Contas da União - TCU, Notícias, 23 ago. 2017. Disponível em: http://portal.tcu.gov.br/imprensa/noticias/aumentam-os-gastos-publicos-comjudicializacao-da-saude.htm. Acesso em: dez. 2017.

${ }^{5}$ MINAS GERAIS. Secretaria de Estado de Saúde. Judicialização da saúde. Belo Horizonte, 2018. Disponível em: http://www.saude.mg.gov.br/judicializacao. Acesso em: 10 ago. 2018.

${ }^{6}$ AUMENTAM os gastos públicos com judicialização da saúde, cit.

${ }^{7}$ VALLE, Gustavo Henrique Moreira do; CAMARGO, João Marcos Pires. A audiência pública sobre a judicialização da saúde e seus reflexos na jurisprudência do Supremo Tribunal Federal. Revista de Direito Sanitário, São. Paulo, v. 11, n. 3, nov. 2010/fev. 2011. http://dx.doi.org/10.11606/issn.2316-9044. v11i3p13-31. Disponível em: http://www.revistas.usp.br/rdisan/article/view/13220.

${ }^{8}$ BALESTRA NETO, Otávio. A jurisprudência dos Tribunais superiores e o direito à saúde - evolução rumo à racionalidade. Revista de Direito Sanitário, São Paulo, v. 16, n. 1, mar./jun. 2015. http://dx.doi.org/10.11606/ issn.2316-9044.v16i1p87-111. Disponível em: http://www.revistas.usp.br/rdisan/article/view/100025.
} 
ligadas à saúde ${ }^{9}$. A partir de então, conclusões alcançadas na audiência pública influenciaram decisões que reafirmaram a jurisprudência do $\mathrm{STF}^{10}$. Dentre elas, destaca-se o Agravo Regimental na Suspensão de Tutela Antecipada (STA) 175/CE de $2010^{11}$. Ao discorrer sobre o julgamento da STA 175/CE, passando por diversas perspectivas envolvidas na questão do direito à saúde, o relator ministro Gilmar Mendes expôs pontos importantes "para a construção de um critério ou parâmetro para a decisão" em matéria de saúde ${ }^{12}$.

Uma vez acertados os critérios que racionalizariam e uniformizariam as decisões e, consequentemente, mudariam a dinâmica do processo de judicialização da saúde ${ }^{13}$, cumpre investigar em que medida eles atingiram seu propósito. Como primeiro passo para a medida da efetividade dos parâmetros racionalizadores da judicialização da saúde estabelecidos na jurisprudência, devem-se investigar sua difusão e sua influência nas decisões dos tribunais. Nessa perspectiva, o presente estudo de caso tem como objetivo verificar o uso da STA 175/CE como referência a embasar as decisões finais colegiadas em processos judiciais em saúde do Tribunal de Justiça do Estado de Minas Gerais (TJMG).

\section{Método}

Trata-se de um estudo de caso realizado com base em dados secundários obtidos nos acórdãos proferidos pelo TJMG, disponíveis no sítio eletrônico do Tribunal. Para identificar o número total de acórdãos que mencionaram a STA 175/CE, foi realizada uma busca por jurisprudência no site do TJMG. Utilizou-se o filtro "acórdão" e a expressão-chave "175 E STA" OU "suspensão de tutela antecipada" expressão esta que retornou o maior número de decisões dentre as expressões-chave elencadas e testadas pelos pesquisadores.

Quando a expressão foi pesquisada no "inteiro teor" dos acórdãos, a busca retornou 4.219 decisões. Já a busca realizada nas ementas retornou 174 decisões.

Em razão do volume de decisões, optou-se por estudar mais detalhadamente apenas os acórdãos que citaram a STA 175/CE em sua ementa, uma vez que a presença na ementa leva à presunção de que a jurisprudência em questão surgiu como argumento decisivo para a decisão final do processo.

Para estimar a magnitude do conjunto de acórdãos com referência à STA 175/CE dentro do universo de acórdãos proferidos pelo TJMG no mesmo

\footnotetext{
${ }^{9}$ SUPREMO TRIBUNAL FEDERAL - STF. Disponível em: http://www.stf.jus.br/portal/cms/verTexto.asp?servic o=processoAudienciaPublicaSaude. Acesso em: 25 set. 2019.

${ }^{10}$ VALLE, Gustavo Henrique Moreira do; CAMARGO, João Marcos Pires. op. cit.

${ }^{11}$ BALESTRA NETO, Otávio. op. cit.

${ }^{12}$ SUPREMO TRIBUNAL FEDERAL - STF. Suspensão de Tutela Antecipada n. 175. Disponível em: http://www. stf.jus.br/arquivo/cms/noticianoticiastf/anexo/sta175.pdf. Acesso em: 21 set. 2016.

${ }^{13}$ BALESTRA NETO, Otávio. op. cit.
} 
período, realizou-se a busca da expressão "direito à saúde" nas ementas dos acórdãos publicados entre 29/09/2009 e 02/08/2018 - respectivamente, a data mais antiga e a mais recente de julgamento dos acórdãos identificados para análise neste estudo.

As informações retiradas de cada acórdão e registradas em planilha foram: número do processo, relator, órgão julgador/câmara, data de julgamento, objeto da ação e contexto de citação da STA 175/CE. As frequências absolutas e relativas de aparição das informações coletadas em relação ao universo da análise foram calculadas.

Foram excluídos do estudo 68 acórdãos nos quais, no momento da análise, não foi verificada, de fato, a referência à STA 175/CE. Em virtude disso, o mesmo erro $(39,1 \%)$ encontrado na busca da expressão-chave para identificar os acórdãos com citação da STA 175/CE foi utilizado na estimativa do universo de acórdãos versando sobre o "direito à saúde".

Por se tratar de uma investigação de dados públicos, não foi necessária a aprovação do Comitê de Ética.

\section{Resultados}

Uma vez que 68 acórdãos foram excluídos no momento da análise por não citarem, de fato, a STA 175/CE, 106 acórdãos compuseram o universo de investigação do estudo.

A citação da STA 175/CE nas ementas dos acórdãos foi verificada em todos os anos desde 2009, tendo sido mais frequente em 2015, 2016 e 2017. Esses três anos consecutivos representaram, juntos, $63,20 \%$ das citações verificadas. O Gráfico 1 ilustra a evolução das referências à STA 175/CE ao longo do período de 29/09/2009 a 02/08/2018 - respectivamente, as datas do primeiro e do último julgamentos analisados no estudo.

Gráfico 1. Número de acórdãos com referência à STA 175/CE verificado de 29/09/2009 a 02/08/2018

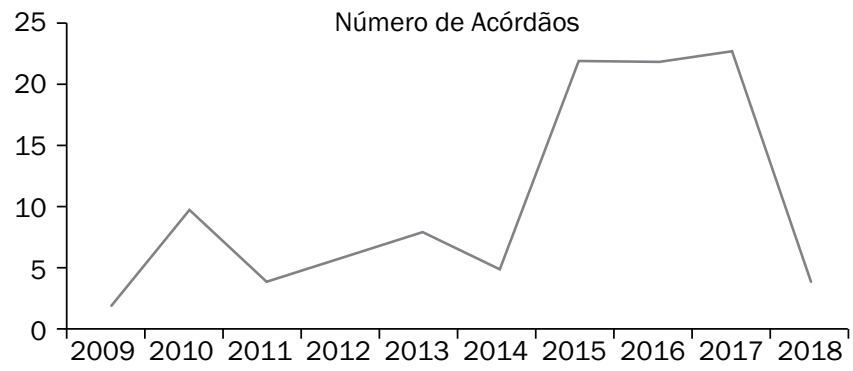

Fonte: TJMG, 2018. Elaboração própria. 
Foram verificados 18 relatores e sete câmaras cíveis onde os acórdãos foram julgados. O menor número de acórdãos relatados por um mesmo desembargador foi um e o maior foi 21. O menor número de acórdãos julgados em uma mesma câmara cível foi dois, enquanto o maior foi 47. Os Gráficos 2 e 3 ilustram a concentração de acórdãos por câmara cível e por relator, respectivamente. Os medicamentos foram o principal objeto de litígio verificado, tendo sido judicializados em $77,36 \%$ dos casos.

Gráfico 2. Porcentagem de acórdãos por câmara cível verificada

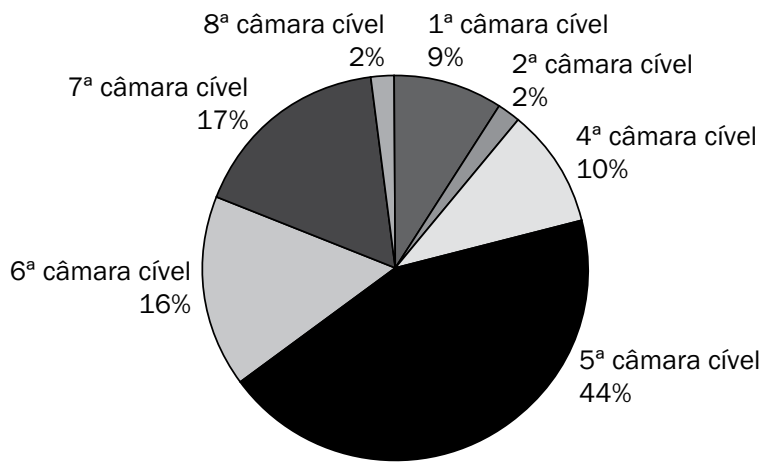

Fonte: TJMG, 2018. Elaboração própria.

Gráfico 3. Número de acórdãos por relator identificado (nomes ocultados)

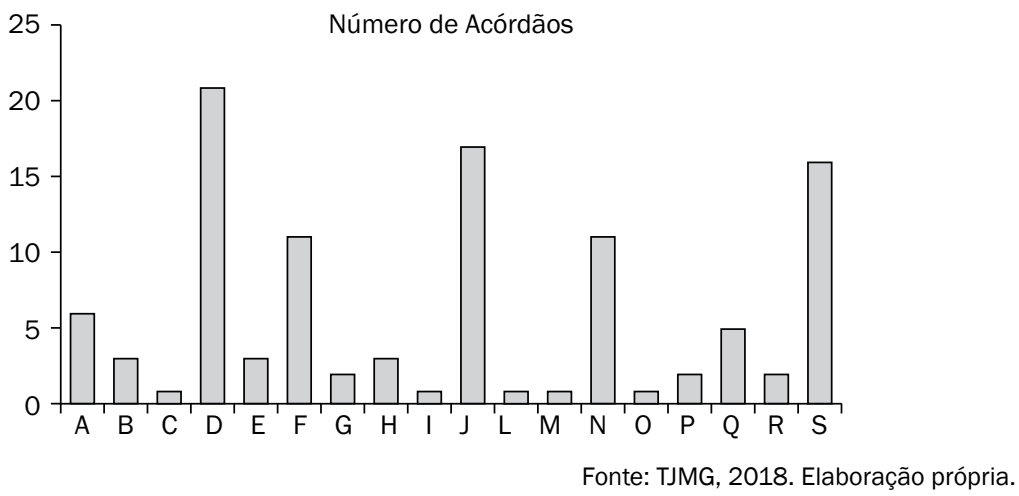

Em relação ao contexto de citação da STA 175/CE, foram verificados quatro tipos de argumentos apoiados na referida jurisprudência. Os relatores dos acórdãos se embasaram uma única vez $(0,9 \%)$ na STA $175 / C E$ para fundamentar a não obrigação 
do Estado de fornecer tratamento experimental sem comprovação científica de eficácia; duas (1,9\%) vezes para afirmar a legitimidade do Judiciário para intervir em matéria de saúde; sete $(6,6 \%)$ vezes para sustentar a responsabilidade solidária entre os entes federados para garantia do direito à saúde; e $96(90,6 \%)$ vezes para declarar a necessidade de priorização dos tratamentos ofertados pelo Sistema Único de Saúde (SUS) e de comprovação, em casos excepcionais, da ineficácia desses tratamentos.

A fim de estimar a magnitude do conjunto de acórdãos com referência à STA 175/CE no universo dos acórdãos versando sobre o direito à saúde no mesmo período, realizou-se a busca em ementas de acórdãos no site do TJMG a partir da expressão "direito à saúde" no período de 29/09/2009 a 02/08/2018. A pesquisa retornou 16.085 acórdãos. Uma vez que, ao analisar os 174 acórdãos identificados na busca de ementas com citações da STA 175/CE foram encontrados 106 acórdãos em que a referência à jurisprudência foi de fato verificada, a mesma margem de erro de $39,1 \%$ foi utilizada para calcular o universo estimado de acórdãos referentes a demandas judiciais em saúde. Assim, estimou-se um universo de 9.799 acórdãos.

Ao comparar o número de acórdãos com referência à STA 175/CE (106) com o universo estimado de acórdãos (9.799), identificou-se que eles representaram $0,1 \%$ do conjunto de acórdãos versando sobre o direito à saúde no mesmo período de estudo.

\section{Discussão}

A fim de melhor discutir os resultados encontrados neste estudo à luz da literatura, propõe-se, inicialmente, apresentar um marco teórico sobre a judicialização do direito à saúde, a Audiência Pública n. 4 de 2009 e a STA 175/CE.

\section{A judicialização e o direito à saúde}

O que quer dizer a expressão “judicialização”? Não é uma tarefa fácil responder a esta questão. Ao que parece, ainda estamos longe de um consenso sobre o sentido do termo ${ }^{14,15}$. Apesar da "vagueza semântica"16 e dos "déficits explicativos"17,

\footnotetext{
${ }^{14} \mathrm{MENICUCCI}$, Telma Maria Gonçalves; MACHADO, José Angelo. Judicialization of health policy in the definition of access to public goods: individual rights versus collective Rights. Brazilian Political Science Review, Rio de Janeiro, v. 4, n. 1, p. 24-68, 2010. Disponível em: http://socialsciences.scielo.org/pdf/s_bpsr/v5nse/scs_a02.pdf.

${ }^{15}$ MACHADO, Felipe Rangel de Souza; DAIN, Sulamis. A Audiência Pública da Saúde: questões para a judicialização e para a gestão em saúde no Brasil. Rev. Adm. Pública, Rio de Janeiro, v.46, n. 4, p. 1017 1036, ago. 2012. http://dx.doi.org/10.1590/S0034-76122012000400006. Disponível em: http://www. scielo.br/scielo.php?script=sci_arttext\&pid=S0034-76122012000400006\&lng=en\&nrm=iso.

${ }^{16}$ SUNDFELD, Carlos Ari et al. Controle de constitucionalidade e judicialização: o STF frente à sociedade e aos poderes. Sociedade Brasileira de Direito Público, Belo Horizonte-MG: Faculdade de Filosofia e Ciências Humanas, 2010. 93p. Disponível em: http://www.sbdp.org.br/wp/wp-content/uploads/2018/01/05controle_de_constitucionalidade_e_judicializacao.pdf.

${ }^{17}$ NOBRE, Marcos; RODRIGUEZ, José Rodrigo. "Judicialização da política”: déficits explicativos e bloqueios normativistas. Novos Estudos CEBRAP, São Paulo, n. 91, p. 5-20, nov. 2011. http://dx.doi. org/10.1590/S0101-33002011000300001. Disponível em: http://www.scielo.br/scielo.php?script=sci_ arttext\&pid=S0101-33002011000300001\&lng=en\&nrm=iso.
} 
parece adequado, para o presente trabalho, pensar a expressão tendo como base a ideia de que o termo se refere a um fenômeno que aponta para uma expansão do Poder Judiciário em razão de uma passagem (ou transferência) de poder decisório do político para o jurídico ${ }^{18,19}$.

Além da problemática conceitual, o processo de expansão dos horizontes da atuação judicial produz muitas controvérsias no que diz respeito a seu desenvolvimento e a seus desdobramentos. Ainda que a tônica inicial tenha sido pautada por defesas entusiasmadas de tal expansão - sob o argumento, básico, de que esse processo contribuiria para a ampliação da efetividade dos direitos fundamentais ${ }^{20}$-, foram desenvolvidas indagações bem estruturadas defendendo que a aparente generosidade presente na expansão do controle judicial poderia esconder "a vontade de domínio, a irracionalidade e o arbítrio cerceador da autonomia dos indivíduos e da soberania popular"21. Nesse sentido, a judicialização poderia estruturar-se "como obstáculo a uma política constitucional libertadora"22.

Sob uma perspectiva crítica, existem também análises que percebem na judicialização um movimento orientado à preservação de certos grupos no poder, visto que o fortalecimento da democracia teria tensionado aspectos centrais de nossa estrutura social ${ }^{23}$. Ademais, são fortes os argumentos que apontam para os riscos que a expansão judicial pode trazer ao sistema democrático ${ }^{24}$.

É nesse complexo debate, portanto, que se situa a judicialização da saúde. No caso brasileiro, a reivindicação judicial pelo direito à saúde teve início com pedidos de medicamentos antirretrovirais e contribuiu para a edição da Lei n. 9.313/199625, que garantiu a distribuição gratuita e universal desses fármacos. Essa vitória inspirou outros movimentos, e a busca pela intervenção judicial no setor saúde cresceu

${ }^{18}$ TATE, C. Neal; VALLINDER, Torbjorn. The global expansion of judicial power. New York; London: New York University Press, 1995.

${ }^{19}$ FEREJOHN, John.Judicializingpolitics politicizinglaw. Lawand ContemporaryProblems, Durham, v.5, n. 3, p. 41-68, 2002. Disponivel em: http://scholarship.law.duke.edu/cgi/viewcontent.cgi?article=1258\&context=lcp.

${ }^{20}$ BARROSO, Luís Roberto. Da falta de efetividade à judicialização excessiva: direito à saúde, fornecimento gratuito de medicamentos e parâmetros para a atuação judicial. In: SOUZA NETO, Cláudio Pereira de; SARMENTO, Daniel (Orgs.). Direitos sociais: fundamentos, judicialização e direitos sociais em espécie. Rio de Janeiro: Lumen Juris, 2008. p. 875-903.

${ }^{21}$ Id. Ibid.

${ }^{22}$ MAUS, Ingeborg. Judiciário como superego da sociedade: o papel da atividade jurisprudencial na 'sociedade órfã'. Novos Estudos CEBRAP, São Paulo, n. 58, p. 183-202, nov. 2000. Disponível em: http:// www.direitocontemporaneo.com/wp-content/uploads/2014/02/JUDICI\%C3\%81RIO-COMO-SUPEREGODA-SOCIEDADE.pdf.

${ }^{23} \mathrm{HIRSCHL}$, Ran. Towards juristocracy: the origins and consequences of the new constitutionalism. Cambridge: Harvard University Press, 2007.

${ }^{24}$ VIANNA, Luiz Werneck et al. A judicialização da política e das relações sociais no Brasil. Rio de Janeiro: Revan, 1999.

${ }^{25}$ BRASIL. Lei n. 9.313, de 13 de novembro de 1996. Dispõe sobre a distribuição gratuita de medicamentos aos portadores do HIV e doentes de AIDS. Disponível em: http://www.planalto.gov.br/ccivil_03/leis/I9313. htm. Acesso em: 25 set. 2019. 
vertiginosamente: de acordo com Delduque e Castro ${ }^{26}$, a judicialização consiste em um "enfrentamento social que ganhou proporções epidêmicas".

Anteriormente à Lei n. 9.313/1996, as reivindicações prestacionais em saúde eram seguidamente negadas ${ }^{27}$. Balestra $\mathrm{Neto}^{28}$, estudando a evolução histórica da jurisprudência do STF e do Supremo Tribunal de Justiça (STJ) em relação ao direito à saúde, observou três distintas fases. A primeira delas iniciou-se na década de 1990, quando o artigo 196 da CF/88 ${ }^{29}$ era considerado uma norma puramente programática e incapaz de produzir efeitos jurídico positivos. A partir dessa interpretação, "a jurisprudência majoritariamente se orientou pela impossibilidade de interferência do Poder Judiciário nas políticas públicas de saúde" ${ }^{30}$, e teses fazendárias relacionadas à impossibilidade financeira estatal de prestação eram predominantemente consideradas. A partir de 1997, principalmente no começo da década de 2000, o artigo 196 passou a ser considerado "uma norma constitucional de plena eficácia" ${ }^{1}$, inaugurando uma nova fase jurisprudencial, na qual as cortes superiores passaram a considerar o princípio da dignidade da pessoa humana como argumento-chave para aprovação das demandas judiciais. O princípio do mínimo existencial passou a ser considerado em detrimento das teses fazendárias e observou-se deferimento em massa das prestações em saúde pleiteadas judicialmente ${ }^{32}$.

Conforme o autor, atualmente, o Brasil estaria vivendo uma terceira fase da interpretação legal do direito à saúde, na qual tem início um movimento que busca "superar a ideia de que o direito à saúde e sua diretriz da integralidade significariam um direito a tudo" ${ }^{33}$. Passa a ser necessária a criação de parâmetros para que a atuação judicial consiga proteger os direitos constitucionais sem deixar de analisar as limitações existentes a sua garantia. Um marco histórico desse novo período se deu com a realização pelo STF, em 2009, da Audiência Pública n. 4, que discutiu medidas para racionalizar a judicialização da saúde ${ }^{34,35}$.

\footnotetext{
${ }^{26}$ DELDUQUE, Maria Célia; CASTRO, Eduardo Vazquez de. A mediação sanitária como alternativa viável à judicialização das políticas de saúde no Brasil. Saúde debate, Rio de Janeiro, v. 39, n. 105, p. 506-513, abr./jun. 2015. http://dx.doi.org/10.1590/0103-110420151050002017. Disponível em: http://www. scielo.br/pdf/sdeb/v39n105/0103-1104-sdeb-39-105-00506.pdf.

${ }^{27}$ GOUVÊA, Marcos Maselli. op. cit.

${ }^{28}$ BALESTRA NETO, Otávio. op. cit.

${ }^{29}$ BRASIL. Constituição da República Federativa do Brasil de 1988. Disponível em: http://www.planalto.gov. br/ccivil_03/Constituicao/Constitui\%E7ao.htm. Acesso em: 25 set. 2019.

${ }^{30}$ BALESTRA NETO, Otávio. op. cit., p. 95.

${ }^{31}$ MACHADO, Felipe Rangel de Souza. op. cit., p. 79.

${ }^{32}$ BALESTRA NETO, Otávio. op. cit.

${ }^{33}$ Id. Ibid. p. 102.

${ }^{34}$ Id. Ibid.

${ }^{35}$ RAMOS, Edith Maria Barbosa; DINIZ, Isadora Moraes; MADUREIRA, Amanda Silva. O Conselho Nacional de Justiça: o Fórum da Saúde e o excesso de judicialização. Caderno Ibero-Americano de Direito Sanitário, Brasília-DF, v. 4, n. 4, out./dez. 2015. http://dx.doi.org/10.17566/ciads.v4i4.224. Disponível em: http:// www.cadernos.prodisa.fiocruz.br/index.php/cadernos/article/view/224.
} 


\section{A Audiência Pública n. 4 de 2009}

Convocada pelo então presidente do STF, ministro Gilmar Mendes, a Audiência Pública n. 4 ocorreu nos dias 27, 28 e 29 de abril e 4, 6 e 7 de maio de 2009. Foram ouvidos 50 especialistas, entre advogados, defensores públicos, promotores e procuradores de justiça, magistrados, professores, médicos, técnicos de saúde, gestores e usuários do SUS.

A fala de abertura de Gilmar Mendes sintetiza a ideia presente na proposta da oitiva:

Se, por um lado, a atuação do Poder Judiciário é fundamental para o exercício efetivo da cidadania e para a realização do direito social à saúde, por outro, as decisões judiciais têm significado um forte ponto de tensão perante os elaboradores e executores das políticas públicas, que se veem compelidos a garantir prestações de direitos sociais das mais diversas, muitas vezes contrastantes com a política estabelecida pelos governos para a área da saúde e além das possibilidades orçamentárias. A ampliação dos benefícios reconhecidos confronta-se continuamente com a higidez do sistema [...]. Em alguns casos, satisfazer as necessidades das pessoas que estão à sua frente, que têm nome, que têm suas histórias, que têm uma doença grave, que necessitam de um tratamento específico, pode, indiretamente, sacrificar o direito de muitos outros cidadãos, anônimos, sem rosto, mas que dependem igualmente do sistema público de saúde ${ }^{36}$.

Entre os diversos pontos discutidos na Audiência envolvendo o direito à saúde e a judicialização, alguns merecem destaque: a responsabilidade solidária entre os entes federados no atendimento às demandas judiciais; a obrigação de prescrição realizada por médico vinculado ao SUS; a necessidade de se procurar a administração pública antes do sistema de justiça para reivindicação de prestações; a restrição a solicitações judiciais de tratamentos fora das listas oficiais e não registrados na Agência Nacional de Vigilância Sanitária (Anvisa), incluindo os tratamentos experimentais; e as fraudes ao SUS.

Gomes et al. ${ }^{37}$ alertam para um emaranhado de interesses que podem ter motivado os discursos de atores representantes de diferentes segmentos durante a audiência. Mesmo assim, houve consenso no debate de alguns pontos, a destacar: a

\footnotetext{
${ }^{36}$ SUPREMO TRIBUNAL FEDERAL - STF. Audiência Pública n. 04, convocada em 05 de março de 2009. Abertura. p. 2. Disponível em: http://www.stf.jus.br/arquivo/cms/processoAudienciaPublicaSaude/anexo/ Abertura_da_Audiencia_Publica_MGM.pdf. Acesso em: 25 set. 2019.

${ }^{37}$ GOMES, Dalila F.et al. Judicialização da saúde e a audiência pública convocada pelo Supremo Tribunal Federal em 2009: o que mudou de lá para cá? Saúde debate, Rio de Janeiro, v. 38, n. 100, p. 139-156, jan./mar. 2014. http://dx.doi.org/10.5935/0103-104.20140008. Disponível em: http://www.scielo.br/ scielo.php?pid=S0103-11042014000100139\&script=sci_abstract\&tIng=pt.
} 
legitimidade de atuação do Poder Judiciário em relação às demandas individuais e a ilegitimidade da requisição por via judicial de tecnologias experimentais ou sem registro na Anvisa ${ }^{38}$.

A audiência pública, como um todo, foi considerada bastante propícia. Logo sua influência começou a ser percebida na jurisprudência do STF, a exemplo do Agravo Regimental na STA 175/CE de 2010 $0^{39,40,41}$, oportunidade na qual o STF objetivou equacionar algumas das tensões decorrentes da judicialização e consolidou, em parâmetros decisórios, várias das questões debatidas durante a audiência pública.

\section{A STA 175/CE}

Trata-se de julgamento de recurso interposto pela União contra indeferimento de pedido de Suspensão de Tutela Antecipada para fornecimento do medicamento Zavesca (miglustat), à época não registrado na Anvisa. O medicamento seria o único indicado para uma jovem de 21 anos de idade, portadora da patologia denominada Niemann-Pick tipo C. A doença neurodegenerativa rara, comprovada clinicamente e por exame laboratorial, causa uma série de distúrbios neuropsiquiátricos, tais como "movimentos involuntários, ataxia da marcha e dos membros, disartria e limitações de progresso escolar e paralisias progressivas" (STA 175/CE).

Os principais argumentos utilizados pela União para recorrer contra a Tutela Antecipada foram o da inexistência de registro do medicamento na Anvisa e a consequente proibição de sua comercialização no país, além da inexistência de protocolo clínico no SUS para o fármaco em questão. Já a família da beneficiária declarou não ter condições de custear o tratamento, orçado em $\mathrm{R} \$ 52.000,00$ por mês. Não constatando "grave lesão à ordem, à economia e à saúde públicas" e verificando a já existência de registro do medicamento na Anvisa à época do julgamento, o ministro Gilmar Mendes indeferiu o recurso da União, mantendo a determinação de fornecimento do medicamento Zavesca à beneficiária pela União, pelo Estado do Ceará e pelo Município de Fortaleza (STA 175/CE).

No julgamento do recurso, ao analisar diversas questões relacionadas ao direito à saúde e à judicialização, o relator buscou estabelecer parâmetros para análise das ações judiciais referentes ao fornecimento de medicamentos e tratamentos pelo SUS. Em síntese, são eles: (i) quando o tratamento já for previsto nas políticas públicas existentes, cabe ao Judiciário garantir seu efetivo cumprimento; (ii) a administração pública não poderá ser condenada a fornecer fármaco que não possua registro na Anvisa; (iii) o fornecimento de um tratamento alternativo a

\footnotetext{
${ }^{38}$ VALLE, Gustavo Henrique Moreira do; CAMARGO, João Marcos Pires. op. cit.

${ }^{39} / d$. Ibid.

${ }^{40}$ BALESTRA NETO, Otávio. op. cit.

${ }^{41}$ GOMES, Dalila F.et al. op. cit.
} 
algum oferecido pelo SUS só poderá ser exigido se for comprovada a ineficácia ou a inadequabilidade, para determinado paciente, do tratamento já oferecido; (iv) o Estado não pode ser condenado a fornecer tratamento experimental, isto é, em fase de pesquisa e sem comprovação científica de sua eficácia; (v) a pretensão a tratamentos não mais considerados experimentais, mas que ainda não foram incorporados pelo SUS, deve ser avaliada cuidadosamente nas respectivas ações individuais e/ou coletivas (STA 175/CE).

O estabelecimento de critérios para racionalizar a análise judicial em saúde teria como objetivo estabelecer um equilíbrio entre as atuações judiciais exageradas e insuficientes. Assim, não poderia o cidadão "esperar o impossível do Estado", mas também não poderia o Estado lhe negar o mínimo existencial, sendo, para isso, fundamental a atuação do Poder Judiciário ${ }^{42}$.

Devido ao caráter uniformizador da jurisprudência do STF, a STA 175/CE teria o poder de influenciar todo o sistema de justiça brasileiro, tornando-se "uma espécie de normativa a ser seguida para as ações que tratam do tema" ${ }^{\text {"3. }}$. Tais parâmetros, portanto, poderiam impulsionar a racionalização das decisões judiciais em matéria de saúde, modificando toda a dinâmica do fenômeno da judicialização ${ }^{44}$.

\section{Discussão dos resultados do estudo}

Balestra Neto 45 indica que a jurisprudência brasileira, no tocante ao direito à saúde e à judicialização, evolui rumo à racionalidade. Valle e Camargo ${ }^{46}$, por sua vez, sustentaram a importância da definição de parâmetros de julgamento, acreditando que eles orientariam as decisões em saúde dos tribunais superiores e dos tribunais do país. No entanto, os resultados do presente estudo indicam que não é possível pressupor que os critérios estabelecidos pelos tribunais superiores estejam sendo utilizados de forma ampla pelo conjunto dos magistrados brasileiros.

Foi observada neste estudo uma difusão restrita da jurisprudência "racionalizadora" da judicialização da saúde no exercício diário dos juízes mineiros. Do universo estimado de 9.799 acórdãos versando sobre o direito à saúde proferidos pelo TJMG entre 29/09/2009 e 02/08/2018, 0,1\% (106) fez referência à STA 175/ CE. Os resultados encontrados em pesquisa realizada pelo Conselho Nacional de Justiça (CNJ) em parceria com o Laboratório de Pesquisas sobre Práticas de Integralidade em Saúde da Universidade do Estado do Rio de Janeiro (Lappis/UERJ) ratificam esse sentido ao apontarem que a maioria das ações judiciais em saúde

\footnotetext{
${ }^{42}$ VALLE, Gustavo Henrique Moreira do; CAMARGO, João Marcos Pires. op. cit., p. 22.

${ }^{43}$ BALESTRA NETO, Otávio. op. cit., p. 94.

${ }^{44}$ Id. Ibid.

${ }^{45}$ BALESTRA NETO, Otávio. op. cit.

${ }^{46}$ VALLE, Gustavo Henrique Moreira do; CAMARGO, João Marcos Pires. op. cit.
} 
ainda se baseia no argumento constitucional máximo de que "saúde é direito de todos e dever do Estado" 47 .

Além disso, observou-se a concentração do uso de referências à jurisprudência por determinados relatores e câmaras cíveis. Uma vez que não se conhece a distribuição dos acórdãos em matéria de saúde por relatores e câmaras, não é possível inferir que a STA 175/CE influenciou de forma mais determinante o conjunto das decisões em saúde relatadas por determinado desembargador. Contudo, o estudo de caso revelou que alguns relatores e órgãos julgadores se embasaram mais frequentemente na STA 175/CE do que outros, o que sugere uma difusão heterogênea da jurisprudência entre os magistrados. Isso pode significar que a discricionariedade do juiz ainda prevalece nas decisões envolvendo o direito à saúde, favorecendo a existência de sentenças judiciais extremamente díspares ${ }^{48}$.

Apesar de a jurisprudência das cortes superiores ter evoluído para uma terceira fase de interpretação do direito à saúde, como identifica Balestra $\mathrm{Neto}^{49}$, os resultados aqui encontrados levantam hipótese de que o momento de racionalidade sugerida pelo autor não necessariamente se refletiu nas decisões dos tribunais, $\mathrm{o}$ que traz grandes incertezas para a gestão em saúde pública. Por se tratar a saúde de algo multidimensional e complexo, o embasamento constitucional puro e simples para decidir sobre a matéria é reducionista, não trazendo à tona o imprescindível enfrentamento das demandas em toda a sua complexidade.

Outro interessante resultado encontrado diz respeito ao contexto de uso da STA 175/CE. Em 96 dos 106 acórdãos estudados, a jurisprudência foi utilizada para declarar que os tratamentos ofertados pelo SUS devem ser priorizados frente às demais alternativas terapêuticas disponíveis no mercado e que os casos excepcionais em que tais tratamentos forem inadequados para o paciente devem ser comprovados. Esse achado parece sugerir que tem sido frequente na judicialização da saúde a discussão das circunstâncias em que um medicamento não contemplado pelo SUS significa um direito do paciente.

Essa hipótese ganha força com a publicação da recente decisão do Superior Tribunal de Justiça (STJ) no Recurso Especial (REsp) n. 1.657.156/RJ, de relatoria do ministro Benedito Gonçalves, que estabeleceu critérios para o fornecimento de medicamentos que não estão contemplados nas listas do SUS. Diferentemente da STA 175/CE, por se tratar de decisão submetida ao rito do artigo 1.036 do Código de Processo de Cível (CPC) $)^{50}$, a decisão do STJ torna-se vinculante para as instâncias

\footnotetext{
${ }^{47}$ ASENSI, Felipe Dutra; PINHEIRO, Roseni (Coords.). Judicialização da saúde no Brasil: dados e experiência. Brasília-DF, Conselho Nacional de Justiça, 2015. Disponível em: http://www.cnj.jus.br/files/conteudo/ destaques/arquivo/2015/06/6781486daef02bc6ec8c1e491a565006.pdf.

${ }^{48}$ RAMOS, Edith Maria Barbosa; DINIZ, Isadora Moraes; MADUREIRA, Amanda Silva. op. cit.

${ }^{49}$ BALESTRA NETO, Otávio. op. cit.

${ }^{50}$ BRASIL. Lei n. 13.105, de 16 de março de 2015. Código de Processo Civil. Disponível em: http://www. planalto.gov.br/ccivil_03/_ato2015-2018/2015/lei/I13105.htm. Acesso em: 01 jul. 2017.
} 
inferiores, conforme previsão do artigo 927, inciso III, do CPC. Assim, a difusão dessa nova jurisprudência poderá ocorrer em uma dinâmica diferente daquela da STA 175/CE, e novos estudos nesse sentido devem ser realizados ${ }^{51}$.

Essa nova jurisprudência deve, ainda, ser estudada a partir de uma outra perspectiva: se, por um lado, a recente decisão do STJ pode trazer ganhos - sobretudo pela maior condição de garantir um padrão para a atuação judicial em todo o território nacional -, por outro, ela traz questões em seu conteúdo que merecem ser cuidadosamente discutidas. É que, além de avançar pouco em relação aos critérios já estabelecidos na STA 175/CE ${ }^{52}$, a decisão, ao exigir a hipossuficiência como condição para fornecimento de medicamento não ofertado pelo SUS - sem que exista previsão constitucional para tanto -, acaba por violar "princípios do SUS e deforma o conceito do direito à saúde quanto à garantia de acesso universal e igualitário"53.

Novas pesquisas devem ser realizadas no sentido de investigar o potencial de as jurisprudências dos tribunais superiores influenciarem as decisões judiciais dos magistrados do país em matéria de saúde. Este estudo de caso apresenta algumas limitações, como o tamanho da amostra, a busca da expressão-chave realizada apenas na ementa e o erro verificado de identificação de jurisprudências no site do TJMG. Contudo, acredita-se que a metodologia utilizada conseguiu levantar resultados importantes, que têm a contribuir para o debate da judicialização da saúde no Brasil.

\section{Considerações finais}

Apesar do caráter uniformizador da jurisprudência dos tribunais superiores, identificou-se que a STA 175/CE não foi referência fortemente utilizada para a tomada de decisões colegiadas em saúde do TJMG no período de 29/09/2009 a $02 / 08 / 2018$. Além disso, seu uso por relatores e órgãos julgadores identificados deu-se de forma heterogênea.

Novas pesquisas devem ser conduzidas para verificar se o caso de Minas Gerais se assemelha a outros estados. Além disso, deve-se investigar se a difusão da nova jurisprudência vinculante recentemente publicada pelo STJ ocorrerá de forma diversa da STA 175/CE e seus efeitos sobre a interpretação do direito à saúde.

Sendo Minas Gerais um dos estados onde o fenômeno da judicialização da saúde atingiu maiores dimensões, acredita-se que os resultados deste estudo de caso sejam importantes e agreguem ao debate da judicialização da saúde. Embora

\footnotetext{
${ }^{51}$ DOURADO, Daniel A. Critérios definidos pelo STJ trazem pouco avanço na judicialização da saúde. Consultor Jurídico [online], maio 2018. Disponível em: https://www.conjur.com.br/2018-mai-03/daniel-douradotese-stj-avanca-judicializacao-saude. Acesso em: ago. 2018.

${ }^{52}$ ld. Ibid.

${ }^{53}$ SANTOS, Lenir. Decisão do STJ sobre medicamento de alto custo deforma conceito do direito à saúde. Consultor Jurídico [online], maio 2018. Disponível em: https://www.conjur.com.br/2018-mai-05/lenirsantos-decisao-stj-medicamento-alto-custo. Acesso em: ago. 2018.
} 
a literatura indique uma tendência à racionalidade na jurisprudência brasileira em relação ao deferimento de prestações em saúde pleiteadas judicialmente, o frágil uso da jurisprudência do STF para embasar as decisões do TJMG não confirma, na prática, tal tendência, pondo em questão a efetividade de tal recurso na intervenção sobre o fenômeno da judicialização da saúde no país.

\section{Referências}

ASENSI, Felipe Dutra; PINHEIRO, Roseni (Coords.). Judicialização da saúde no Brasil: dados e experiência. Brasília-DF, Conselho Nacional de Justiça, 2015. Disponível em: http://www.cnj. jus.br/files/conteudo/destaques/arquivo/2015/06/6781486daef02bc6ec8cle491a565006.pdf.

AUMENTAM os gastos públicos com judicialização da saúde. Tribunal de Contas da União - TCU, Notícias, 23 ago. 2017. Disponível em: http://portal.tcu.gov.br/imprensa/noticias/ aumentam-os-gastos-publicos-com-judicializacao-da-saude.htm. Acesso em: dez. 2017.

BALESTRA NETO, Otávio. A jurisprudência dos Tribunais superiores e o direito à saúde evolução rumo à racionalidade. Revista de Direito Sanitário, São Paulo, v. 16, n. 1, mar./jun. 2015. http://dx.doi.org/10.11606/issn.2316-9044.v16ilp87-111. Disponível em: http://www. revistas.usp.br/rdisan/article/view/100025.

BARROSO, Luís Roberto. Da falta de efetividade à judicialização excessiva: direito à saúde, fornecimento gratuito de medicamentos e parâmetros para a atuação judicial. In: SOUZA NETO, Cláudio Pereira de; SARMENTO, Daniel (Orgs.). Direitos sociais: fundamentos, judicialização e direitos sociais em espécie. Rio de Janeiro: Lumen Juris, 2008. p. 875-903.

DELDUQUE, Maria Célia; CASTRO, Eduardo Vazquez de. A mediação sanitária como alternativa viável à judicialização das políticas de saúde no Brasil. Saúde debate, Rio de Janeiro, v. 39, n. 105, p. 506-513, abr./jun. 2015. http://dx.doi.org/10.1590/0103-110420151050002017. Disponível em: http://www.scielo.br/pdf/sdeb/v39n105/0103-1104-sdeb-39-105-00506.pdf.

DOURADO, Daniel A. Critérios definidos pelo STJ trazem pouco avanço na judicialização da saúde. Consultor Jurídico [online], maio 2018. Disponível em: https://www.conjur.com. br/2018-mai-03/daniel-dourado-tese-stj-avanca-judicializacao-saude. Acesso em: ago. 2018.

FEREJOHN, John. Judicializing politics politicizing law. Law and Contemporary Problems, Durham, v. 5, n. 3, p. 41-68, 2002. Disponível em: http://scholarship.law.duke.edu/cgi/ viewcontent.cgi?article $=1258 \&$ context $=$ lcp.

GOMES, Dalila F.et al. Judicialização da saúde e a audiência pública convocada pelo Supremo Tribunal Federal em 2009: o que mudou de lá para cá? Saúde debate, Rio de Janeiro, v. 38, n. 100, p. 139-156, jan./mar. 2014. http://dx.doi.org/10.5935/0103-104.20140008. Disponível em: http://www.scielo.br/scielo.php?pid=S0103-11042014000100139\&script=sci_abstract\&tlng=pt.

GOUVÊA, Marcos Maselli. O direito ao fornecimento estatal de medicamentos. Revista Forense, Rio de Janeiro, v. 99, n. 370, p. 103-134, nov./dez. 2003. [BuscaLegis.ccj.ufsc.br]. Disponível em: http://www.egov.ufsc.br/portal/sites/default/files/anexos/15709-15710-1-PB.pdf. 
HIRSCHL, Ran. Towards juristocracy: the origins and consequences of the new constitutionalism. Cambridge: Harvard University Press, 2007.

MACHADO, Felipe Rangel de Souza. Contribuições ao debate da judicialização da saúde no Brasil. Revista de Direito Sanitário, São Paulo, v. 9, n. 2, p. 73-91, jul./out. 2008. http:// dx.doi.org/10.11606/issn.2316-9044.v9i2p73-91. Disponível em: http://www.revistas.usp.br/ rdisan/article/view/13118.

MACHADO, Felipe Rangel de Souza; DAIN, Sulamis. A Audiência Pública da Saúde: questões para a judicialização e para a gestão em saúde no Brasil. Rev. Adm. Pública, Rio de Janeiro, v.46, n. 4, p. 1017-1036, ago. 2012. http://dx.doi.org/10.1590/S0034-76122012000400006. Disponível em: http://www.scielo.br/scielo.php?script=sci_arttext\&pid=S0034-76122012000400006\&ln $\mathrm{g}=\mathrm{en} \& \mathrm{nrm}=$ iso.

MAUS, Ingeborg. Judiciário como superego da sociedade: o papel da atividade jurisprudencial na 'sociedade órfã'. Novos Estudos CEBRAP, São Paulo, n. 58, p. 183-202, nov. 2000. Disponível em: http://www.direitocontemporaneo.com/wp-content/uploads/2014/02/ JUDICI\%C3\%81RIO-COMO-SUPEREGO-DA-SOCIEDADE.pdf.

MENICUCCI, Telma Maria Gonçalves; MACHADO, José Angelo. Judicialization of health policy in the definition of access to public goods: individual rights versus collective Rights. Brazilian Political Science Review, Rio de Janeiro, v. 4, n. 1, p. 24-68, 2010. Disponível em: http://socialsciences.scielo.org/pdf/s_bpsr/v5nse/scs_a02.pdf.

MINAS GERAIS. Secretaria de Estado de Saúde. Judicialização da saúde. Belo Horizonte, 2018. Disponível em: http://www.saude.mg.gov.br/judicializacao. Acesso em: 10 ago. 2018.

NOBRE, Marcos; RODRIGUEZ, José Rodrigo. “Judicialização da política”: déficits explicativos e bloqueios normativistas. Novos Estudos CEBRAP, São Paulo, n. 91, p. 5-20, nov. 2011. http:// dx.doi.org/10.1590/S0101-33002011000300001. Disponível em: http://www.scielo.br/scielo. php?script=sci_arttext\&pid=S0101-33002011000300001\&lng=en\&nrm=iso.

RAMOS, Edith Maria Barbosa; DINIZ, Isadora Moraes; MADUREIRA, Amanda Silva. O Conselho Nacional de Justiça: o Fórum da Saúde e o excesso de judicialização. Caderno Ibero-Americano de Direito Sanitário, Brasília-DF, v. 4, n. 4, out./dez. 2015. http://dx.doi. org/10.17566/ciads.v4i4.224. Disponível em: http://www.cadernos.prodisa.fiocruz.br/index. $\mathrm{php} /$ cadernos/article/view/224.

SANTOS, Lenir. Decisão do STJ sobre medicamento de alto custo deforma conceito do direito à saúde. Consultor Jurídico [online], maio 2018. Disponível em: https://www.conjur. com.br/2018-mai-05/lenir-santos-decisao-stj-medicamento-alto-custo. Acesso em: ago. 2018.

SUNDFELD, Carlos Ari et al. Controle de constitucionalidade e judicialização: o STF frente à sociedade e aos poderes. Sociedade Brasileira de Direito Público, Belo Horizonte-MG: Faculdade de Filosofia e Ciências Humanas, 2010. 93p. Disponível em: http://www. sbdp.org.br/wp/wp-content/uploads/2018/01/05-controle_de_constitucionalidade_e_ judicializacao.pdf. 
SUPREMO TRIBUNAL FEDERAL - STF. Audiência Pública n. 04, convocada em 05 de março de 2009. Abertura. Disponível em: http://www.stf.jus.br/arquivo/cms/ processoAudienciaPublicaSaude/anexo/Abertura_da_Audiencia_Publica__MGM.pdf. Acesso em: 25 set. 2019.

TATE, C. Neal; VALLINDER, Torbjorn. The global expansion of judicial power. New York; London: New York University Press, 1995.

VALLE, Gustavo Henrique Moreira do; CAMARGO, João Marcos Pires. A audiência pública sobre a judicialização da saúde e seus reflexos na jurisprudência do Supremo Tribunal Federal. Revista de Direito Sanitário, São. Paulo, v. 11, n. 3, nov. 2010/fev. 2011. http://dx.doi. org/10.11606/issn.2316-9044.v11i3p13-31. Disponível em: http://www.revistas.usp.br/rdisan/ article/view/13220.

VENTURA, Miriam et al. Judicialização da saúde, acesso à justiça e a efetividade do direito à saúde. Physis [online], Rio de Janeiro, v. 20, n. 1, p. 77-100, jan./fev. 2010. http://dx.doi. org/10.1590/S0103-73312010000100006. Disponível em: http://www.scielo.br/scielo. php?pid=S0103-73312010000100006\&script=sci_abstract\&tlng=es.

VIANNA, Luiz Werneck et al. A judicialização da política e das relações sociais no Brasil. Rio de Janeiro: Revan, 1999.

Luciana de Melo Nunes Lopes - Doutoranda em Saúde Pública pela Universidade Federal de Minas Gerais (UFMG); mestrado em Saúde Pública pela UFMG. Diretora Executiva da Universidades Aliadas por Medicamentos Essenciais (UAEM Brasil). Farmacêutica. Belo Horizonte/MG, Brasil.E-mail: lucianamnlopes@gmail.com

Tiago Lopes Coelho - Doutorando em Saúde Pública pela Universidade Federal de Minas Gerais (UFMG) ); mestrado em Saúde Pública pela UFMG. Advogado. Belo Horizonte/MG, Brasil.

Semíramis Domingues Diniz - Mestrado em Saúde Pública pela Universidade Federal de Minas Gerais (UFMG). Farmacêutica. Belo Horizonte/MG, Brasil.

Eli Iola Gurgel de Andrade - Doutorado em Demografia pela Universidade Federal de Minas Gerais (UFMG). Professora Titular da Faculdade de Medicina da UFMG. Coordenadora do Grupo de Pesquisa em Economia da Saúde da UFMG (GPES/UFMG). Economista. Belo Horizonte/MG, Brasil. 